\title{
LA IGLESIA DE SANTA MARÍA MAGDALENA DE SEVILLA: ORGANOLOGÍA E ICONOGRAFÍA MUSICAL
}

\section{THE CHURCH OF SANTA MARÍA MAGDALENA IN SEVILLE: ORGANOLOGY AND MUSICAL ICONOGRAPHY}

\author{
$\mathrm{M}^{\mathrm{a}}$ DEl CARMen RodríGuez Oliva \\ Instituto Andaluz de Patrimonio Histórico. España \\ ORCID: 0000-0002-0194-7998 \\ mcarmen.ro.iaph@gmail.com
}

\begin{abstract}
El tema de este estudio es el análisis de la iconografía y la organología de la parroquia de Santa María Magdalena de Sevilla. Nos acercaremos a los instrumentos musicales que aparecen y accederemos a conocer la estructura, construcción, perfeccionamiento o formas de "hacer música" en dicha iglesia. En nuestra opinión, un instrumento musical funciona como un atributo para identificar la obra de arte y su iconografía. Estas representaciones suelen proporcionar gran exactitud de la instrumentación garantizando las prácticas interpretativas, aunque a veces prevalece el valor estético sobre la autenticidad instrumental y sonora. Se propone una reflexión no solo sobre pinturas o esculturas, sino también sobre los diferentes espacios donde se intuye una actividad musical singular de la parroquia.
\end{abstract}

Palabras clave: dominicos; iglesia de Santa María Magdalena de Sevilla; música; iconografía; organología; pinturas.

The subject of this study is the analysis of the iconography and organology of the church of Santa María Magdalena in Seville. We will approach the musical instruments that appear and we will access the structure, construction, improvement or ways of "making music" in that Church. In our opinion, a musical instrument functions as an attribute to identify the work of art and its iconography. These representations usually provide great accuracy of the instrumentation guaranteeing the interpretive practices, although sometimes the aesthetic value prevails over the instrumental and sonic authenticity. A reflection is proposed not only on paintings or sculptures, but also on the different spaces where a singular musical activity of the Parish is sensed.

Keywords: Dominicans; Church of Santa Maria Magdalena in Seville; music; iconography; organology; paintings. 
La Música es el resultado intencionado de la combinación temporal entre sonidos y silencios. Y debido al carácter intangible y etéreo del sonido, todas las culturas la han asociado a lo sobrenatural y trascendente. No es casualidad que sean ángeles, los mensajeros y mediadores entre lo divino y lo humano, los que aparezcan representados artísticamente interpretando o portando instrumentos musicales, reflejando así la unión entre lo terrenal y lo espiritual de la existencia en toda su dimensión.

$\mathrm{M}^{\mathrm{a}}$ Isabel Osuna

Si imaginamos una columna de tiempo donde las fases estratigráficas queden señaladas a modo de historia oculta del pasado y después de fundamentar una literatura, exigua por sorpresa y casi inconcebible por su importancia, que ilustra la intrahistoria de un Bien de Interés Cultural como es la actual iglesia parroquial de Santa María Magdalena de Sevilla; nos encontraríamos con un primer nivel rodeado de ciertas leyendas sobre una posible mezquita donde se construyó el templo primitivo en torno al mítico San Fernando, templo hoy desaparecido. Un segundo nivel nos hablaría de la construcción del convento dominico de San Pablo el Real del que sí, la historiografía, ha dado constancia histórica con amplias descripciones de sus dependencias ${ }^{1}$; buena cuenta de ello nos ofrece el viajero y dominico francés el Padre Labat en su viaje por Andalucía de principios del siglo XVIII que comentaba: "San Pablo más que un convento parece una villa" 2 . Se habla reiteradamente sobre todo del hoy inexistente claustro destruido relativamente no hace muchos lustros.

En el nivel actual la iglesia conserva huellas de ese pasado del conjunto conventual que siempre se vio favorecido a lo largo de su historia por la aristocracia sevillana. A pesar de ello no se mantendrá en el tiempo, debido en gran parte a los vecinos de frontera francesa que acarrearon una época turbulenta para España, además de las nuevas políticas de ensanches y la posterior desidia. Todas estas circunstancias condujeron a la desaparición de la casi totalidad del convento. Solo contamos con datos que parecen casuales, la mayoría referidos a su historia arquitectónica ${ }^{3}$, el resto queda en penumbra, sobre todo en cuanto a la exploración de aspectos sonoros que han quedado invisibles. Actualmente en la parroquia de la Magdalena, como es conocida habitualmente, sólo queda una estela de lo que fue, con algunos testigos incluso estructurales muy interesantes para nuestra aportación como son el espacio dedicado a los coros o el de los órganos, lugares que salvaguardó la última actuación de Leonardo de Figueroa. Este arquitecto del barroco sevillano mantuvo una doble visión muy patrimonial, por una parte el respeto de conservación de restos de elementos antiguos y por

\footnotetext{
${ }^{1}$ Roda Peña, 2016: 193-232.

2 Labat, 2007: 365.

3 Montoya Alabau, 2009: 295-340.
} 
otra la formalización de uno de los templos barrocos más significativos de la ciudad. Ciertamente, la parroquia que hoy vemos lleva el sello y las trazas de Leonardo de Figueroa, arquitecto que protegió de alguna manera la idiosincrasia de lo que supuso ese antiguo convento dominico de San Pablo. En su interior se percibe ese extenso programa preconcebido a partir de todo lo que rodea al mundo dominico, expuesto en un programa pictórico donde se describe la vida y obra del apóstol San Pablo y el poder de la orden dominica.

Todo esto es especialmente significativo para nosotros y, desde una mirada analítica, se puede descubrir la importancia que ha tenido la música para la orden y especialmente el canto litúrgico, ya que la música formaba parte de la oración misma y no se concebía una liturgia que no fuera cantada ${ }^{4}$. La música y el canto son realidades fundamentales para los dominicos que ven cómo la celebración litúrgica se convierte en el "Cántico Nuevo del Apocalipsis" (Ap. 5,19) que por vocación hace una continua alabanza a Dios...De hecho, para los dominicos el fervor musical se mantendrá siempre, así nos encontramos que a finales del siglo XIX se insiste en la obligación de cantar todo el Oficio. Efectivamente, en el inventario que se realizaría en 1835 para el traslado de la parroquia a la antigua iglesia del convento de San Pablo y actual parroquia de la Magdalena vemos que se mantendrán los dos coros, cada uno con su facistol y los dos órganos, por lo que no dudamos de un uso normalizado ${ }^{5}$. Como es natural podemos pensar en una evolución compositiva y práctica de la música de acuerdo con la propia de su trayectoria histórica-estética, como por ejemplo el paso de los pasajes planos a otros más adornados, etc.

Efectivamente esta concepción de la música y el canto es fundamental para comprender la iconografía musical de la iglesia de la Magdalena y que Leonardo de Figueroa nos ha dejado patente desde el siglo XVIII. Si volvemos la vista atrás, nos gustaría encontrar esas percepciones que miden el significado de ese concepto musical y que está en relación directa con las actividades musicales que se ejercían. De esta forma, nos encontramos al final de la iglesia un coro bajo y, elevado sobre él, otro gran espacio de coro alto dedicado al canto y conectado con dos capillas contiguas a modo de tribunas abiertas hacia las naves laterales ${ }^{6}$. Esta multiplicación de espacios corales y, en consonancia con lo expresado por Francisco Pinto, nos proporciona una extensión del coro que articula de alguna forma el espacio musical ${ }^{7}$. Esa prolongación del espacio en lo acústico se concretaría en los determinados lugares que ocuparían las voces, los ministriles y otros

${ }^{4}$ Peñas Serrano, 2005: 255-316.

${ }^{5}$ Martín Pradas, 2004: 209-257.

${ }^{6}$ Roda Peña, 2016: 193-232. "se localizaba el coro bajo, con su bóbeda de cantería, reja, que le hazían mui vistoso, y sobre él caía el alto con su sillería a lo moderno de caoba y ciprez mui pulida y bien labrada".

7 Pinto Puerto, 2015: 357. 
acompañamientos instrumentales que junto a la sonoridad del órgano provocaría una verdadera resonancia acústica a modo de caja de música, imprimiendo con todos estos componentes musicales una auténtica explosión sonora en la iglesia.

Hay que hacer hincapié que estamos en la época de la policoralidad, propia de la estética barroca e igualmente recordemos el lema dominico de "cantar las horas canónicas y divinos oficios"8. Indiscutiblemente esa proyección de espacios de extensa sonoridad que se ha descrito se aprovecharía para los cantos de oficios, misas y también para diferentes celebraciones más solemnes. Cabe imaginarse la grandiosidad de estos coros cantando y alabando a Dios como su principal misión, pero no podemos olvidar que esos exegetas musicales interpretaban en vivo siendo la música un placer privativo del público que acudía. Cantos y música instrumental debían facilitar la introspección, concentración y devoción a los fieles que acudían a la ceremonia y a la vez un deleite para los sentidos. En general, y sin entrar en pormenores, se constata que la interpretación musical formaba parte de la rutina, del día a día de la iglesia ${ }^{9}$. Regularmente el coro podía solemnizar la liturgia interpretando de forma solista (sochantre), de forma responsorial (alternancia del sochantre y del coro) o antifonal (alternancia entre dos coros). Fundamentalmente se cantaban las horas canónicas, es decir, los cantos del oficio del día: Laudes, Prima, Tercia, Sexta, Nona, Vísperas, Completas y Maitines. También se podían cantar en gregoriano los cantos del propio de la Misa (Introito, Gradual, Alleluia, Tracto, Secuencia, Ofertorio y Comunión) y del Ordinario (Kyrie, Gloria, Credo, Sanctus, Benedictus y Agnus Dei) ${ }^{10}$.

Todas estas visiones sonoras vienen confirmadas por diferentes notas de los libros de cuentas y noticias, así "en el Acta de Cabildo del 9 de enero de 1693, se presentan a la oposición para ocupar la vacante de maestro de capilla de la Iglesia del Salvador Dn. Diego de Aguilar, presbitero, Maestro de Capilla y Canónigo de la Catedral de Lugo, y Dn. Gabriel García, clérigo de menores y Maestro de Capilla de la Iglesia de la Magdalena...” o, en ese mismo año de 1693 Pedro Irisarri y Taso era cantor de la iglesia de la Magdalena y Sebastián de Miranda músico, igualmente en 1688 Francisco Díaz de Alcoba era ministril sacabuche ${ }^{11} \ldots$, y así seguiría una amplia nómina de músicos que corrobora no solo la existencia de esa capilla musical sino también esas amplias actividades dedicadas a la música.

${ }^{8} \mathrm{http} / / / \mathrm{www} . \mathrm{historicalsoundscapes.com/evento/802/sevilla/es} \mathrm{(12-09-2020).}$

${ }^{9}$ En el Archivo de la parroquia de Sta. M Magdalena (APSMMS) hemos constatado en diversos libros de cuentas que se realizaban eventos, fiestas y conciertos. También desde 1698 hasta el s. XIX el pago a cuentas de coros y músicos, sobre todo organistas como Gabriel Roses desde 1698 hasta 1710, Nicolás Navarro en 1718, Frco. Gutiérrez desde 1803 hasta 1809 o Manuel Velazco en 1810.

${ }^{10}$ Isusi Fagoaga, 2020: 65.

${ }^{11}$ Gutiérrez Cordero, 2008: 158-298. 
Verdaderamente si se presta atención se redescubrirá un auténtico paisaje sonoro propio y particular de la iglesia y se puede suponer que la probable capilla musical de la parroquia de la Magdalena, junto a la catedralicia, la colegial de San Salvador y la parroquia de Santa Ana serían las más importantes de la ciudad. En general se puede decir que el estamento eclesiástico fue el mayor productor/consumidor de música en esta época, sin olvidar que la realidad de estas condiciones de la acústica y de estos espacios religiosos han evolucionado a lo largo de la historia, fundamentalmente por las exigencias litúrgicas impuestas por la evolución del pensamiento religioso y por las tendencias artísticas en general y arquitectónicas en particular que se dan en cada momento de la historia.

Sería en ese ámbito Barroco en el que observaríamos la gran capacidad de esos espacios musicales. Así pues, considerando los espacios de música hasta ahora descritos tendríamos: por una parte, ese coro alto que tenía una extraordinaria sillería de doble cuerpo con 82 asientos, hoy en el convento de la Asunción de Calatrava de la ciudad de Almagro ${ }^{12}$, y por otra parte el coro bajo que en algún momento llegarán hasta 33 sitiales. Todo esto implica un gran aforo destinado para el canto. Además, contemporáneo y acorde con la generosa sillería, se aprecia el soberbio facistol (actualmente en la iglesia) de gran tamaño (4 metros de altura), donde se colocaban los grandes volúmenes de libros de coro y que también nos asegura la gran participación de lectores músicos.

Actualmente solo nos quedan los rastros de esos espacios que fueron relegados a nuevos usos. Pero perseveramos en nuestra idea de recoger la actividad musical de la iglesia de la Magdalena y nada más entrar por sus portones, se hace patente la música con la aparición de dos tribunas con dos órganos delante del coro a ambos lados de la nave central, descritos por Hernández Díaz "En los tramos antes coro, dos grandes órganos, con sus correspondientes tribunas, decoradas a tono con lo demás. La caja del más ornamentado fue construida 1739 a 1741 por Luis de Vilches, arquitecto y escultor, y el otro procede de la extinguida parroquia de la Magdalena"13. Del traslado del órgano se encargará el maestro organero V. Verdolaga en $1810^{14}$. También Ayarra nos hizo una descripción más técnica ${ }^{15}$. Realmente se trata de dos órganos del siglo XVIII, el más antiguo con el escudo dominico de la cruz, rematando sus extremos con la flor de lis y el otro de formas mixtilíneas con trazas más neoclásicas. La caja de ambos forma una pieza de grandes proporciones con teclado y sacarregistros ubicados en el zócalo, la tubería exterior vertical con torreones de diferentes planos, el primer cuerpo: los horizontales o de batalla en el arranque, y los verticales en cinco calles, siendo la central de mayor altura. Estos dos órganos representan la magnificencia de la

\footnotetext{
12 Martín Pradas, 2004: 273-281.

${ }_{13}$ Hernández Díaz, 1989: 203-236.

${ }_{14}$ Martín Pradas, 2004: 274.

15 Ayarra Jarne, 1998: 389-291.
} 
iglesia que, de alguna forma, pretende emular la sonoridad de la catedral hispalense. (Figura 1).

Si a nivel estructural nos encontramos esos espacios acústicos dedicados a diferentes actividades musicales en cuyo espacio temporal concurrían esas manifestaciones sonoras referidas más arriba, en el plano plástico rescatamos también ciertos aspectos pictóricos de interés. Mediante el análisis iconográfico/organológico de diferentes representaciones artísticas, se puede conocer la estructura, construcción, características, los modos de hacer y tocar, e indagar en el mundo sonoro de su tiempo.

Recordemos que en la iglesia de la Magdalena la comunidad dominica expresará su sentido de la estética con un lenguaje barroco mediante nuevas propuestas decorativas que cubren todos los muros de la iglesia, sin olvidar los principios doctrinales del ideario dominico. La decoración la llevarán a cabo discípulos de Valdés Leal, un taller con Lucas Valdés (1661-1725) a la cabeza, que se encargará de pintar todos los muros de la iglesia, bóvedas, soportes, coros, sacristía, etc. ${ }^{16}$. Todo un extenso programa iconográfico con un lenguaje pictórico lleno de elementos ornamentales, inscripciones latinas, escenas bíblicas, muchos fingidos como hornacinas, etc., con temas relacionados con la Orden de Santo Domingo, los misterios del Rosario y los apóstoles ${ }^{17}$. Ciertamente, la mano de Lucas Valdés se aprecia sobre todo en la habilidad para describir la acción y dar plasticidad a sus figuras pintadas en los muros. Este pintor tenía una técnica muy depurada al temple con un apropiado uso del color y cierta fuerza expresiva que en muchos casos se atenúa por la serenidad de las expresiones de sus personajes. Como digno sucesor de su padre mantuvo en el siglo XVIII las formas propias y la versatilidad del arrebatador barroco, alejándose de alguna forma de la exitosa plástica murillista del momento.

Justamente nos detendremos en las tribunas donde se asientan los órganos de la parroquia. Estas tribunas siguen el mismo criterio plástico de toda la iglesia, están decoradas con pinturas murales de mediados de siglo XVIII, probablemente realizadas por un anónimo colaborador de esos pintores restantes del taller y en ellas encontramos una sugerente iconografía musical. (Figura 2)

Desde el altar mayor, si observamos la tribuna de la derecha, se podrán comprobar una serie de pinturas murales con motivos organológicos. En la zona central de la tribuna se distingue la representación de Santa Cecilia con sus atributos propios: iconográficamente aparece representada con la palma (símbolo de los mártires) que sostiene sobre una mano mientras que la otra mano se muestra en espera; le acompaña su distintivo iconográfico, un órgano al que se aprecian los tubos y las teclas negras/blancas del teclado.

${ }^{16}$ Fuentes Lázaro, 2010: 195-210.

${ }^{17}$ Fernández López, 2004: 50-57. 
Realmente la Santa está interpretando música y por ello nos enseña la mano, su mirada está expectante como si estuviese esperando la entrada de la parte del órgano, ya que a los lados se desarrolla una zona con una pequeña corte de ángeles músicos y cantores. Santa Cecilia justo aguarda su entrada en ese cuarteto formado por: dos ángeles niños o querubines cantores, muy ligeros de ropas que sostienen entre sus manos libros de partituras (llamada de atención como música culta). En esas partituras se muestran visiblemente grafías musicales, las líneas de los pentagramas, claves, algunos compases y notas de música instrumental, aunque ciertamente no se corresponde con ninguna pieza real ${ }^{18}$; Siguen otros dos ángeles mancebos vestidos con túnicas vaporosas y agitadas por el movimiento, estos portan instrumentos que componen el acompañamiento de cuerdas.

Estos dos ángeles músicos están afanados en su desempeño, creando una melodía celestial. A un lado, un ángel violinista ejecuta música con un violín plenamente definido, tiene cuatro cuerdas, la caja de resonancia con orificios en forma de "f", un clavijero recto con la voluta típica del instrumento. Esta iconografía nos ofrece un pleno desarrollo morfológico y estético del instrumento, además la forma del tañido del ángel tiene un elevado grado de fidelidad con respecto a la interpretación real; es bastante correcta con una buena posición de manos por lo que la ejecución es muy adecuada. Musicalmente el ángel violinista lo tañe al hombro con una posición de manos que muestran la interpretación musical presionando los dedos de la mano izquierda las cuerdas del diapasón y la derecha deslizando el arco que está aún ligeramente curvado y estilizado, esta tipología de arco imprime cierto arcaísmo. Sin duda, el violinista imprime expresividad y sonoridad al concierto, no olvidemos que en el Barroco se establece la tonalidad de la melodía a través del violín, por lo que el ángel violinista está marcando las recreaciones de la melodía más aguda. Ciertamente, a partir del Barroco, el violín nos ofrece la potencia del sonido más la agilidad de ornamentación melódica, con un espectacular desarrollo de la tesitura aguda. El violín y el violón comenzaron a sonar en las iglesias a lo largo de la segunda mitad del siglo XVII y fueron ocupando un lugar cada vez más destacado a lo largo del siglo XVIII ${ }^{19}$. Se puede pensar que en este "concierto", posiblemente en muchos momentos adquirirá un papel fundamental como solista. (Figura 3)

Al otro lado, un ángel chelista ejecutando música con un violonchelo que por sus características concretas no se puede confundir con la viola da gamba, ambos coexistieron más de un siglo y compartieron algunos rasgos comunes, pero en nuestra pintura las particularidades del violonchelo están bien diferenciadas: cuatro cuerdas supuestamente afinadas por quintas, (se observa que están perfectamente dibujadas, tensadas y fijadas al clavijero), carece de trastes, tiene orificios de resonancia en forma de "S" (debido a su forma parecida a esta letra) y

\footnotetext{
${ }^{18}$ Rodríguez Oliva/Osuna Lucena/Sánchez Rodríguez, 2018: 80-89.
}

19 Isusi Fagoaga/Gembero Ustárroz, 2002: 105. 
el clavijero termina en forma de una voluta amplia. El violonchelo tiene un papel fundamental en el conjunto de las cuerdas aportando la profundidad de timbre. El instrumento lo sostiene sobre las piernas y es tañido de forma que denominaríamos "a lo antiguo". Se puede apreciar la distancia entre los dedos y cómo los presiona sobre las cuerdas del mástil para su interpretación. El arco que nos muestra es bastante curvo de morfología primitiva, tanto por la forma de coger el instrumento, como la forma de tocar, se aprecia perfectamente que el ángel músico está ejecutando una melodía grave que formaría parte del bajo continuo de acuerdo con la estética barroca que estamos comentando. (Figura 4).

Por otra parte, en la tribuna izquierda, se conservan otras pinturas murales que contribuyen a imaginar el engrandecimiento de una auténtica orquesta. En el centro se muestra al rey David tocando el arpa. Sobre esta iconografía y análisis organológico se volverá más adelante, en este caso solo reseñar que por tamaño se trata de un arpa medieval, pero con decoración de roleos muy barrocos, una mezcla bastante inverosímil y con cierta improvisación artística, cuya práctica se hace imposible de interpretar en la realidad porque las cuerdas graves del centro están ampliamente separadas. Sí se debe resaltar la correcta postura y posición de las dos manos que están pulsando las cuerdas con los dedos. El arpa será uno de los instrumentos más representados y será motivo de inspiración de los más grandes artistas del cristianismo en sus más variadas expresiones, en el caso que nos ocupa, está asociado con lo celestial, lo virtuoso y lo sublime creando una música ciertamente inspiradora de sonidos espirituales.

A ambos lados del rey David aparecen rollizos angelotes músicos, dos de ellos sostienen las partituras cuyas grafías se han perdido pero que mostrarían las notas musicales. Estos ángeles sirven a modo de atril para los ángeles que están interpretando. Uno de ellos tañe una trompeta o añafil que en principio se podría confundir con una chirimía, pero no se aprecian ni los orificios, ni la boquilla por lo que se descarta. Además, el añafil se toca directamente en boca como lo realiza nuestro ángel músico.

Estamos hablando de un instrumento musical de viento de metal, un aerófono recto que precisamente se caracteriza porque no presenta orificios, ni llaves, ni ningún otro elemento constructivo que sirva para alterar la afinación o el timbre. Este añafil o trompeta natural alargada se parece a la tuba romana cuyo uso era propiamente militar, uso que con el tiempo irá perdiendo. De hecho, estas trompetas rectas ocupan un lugar muy destacado en las Sagradas Escrituras, especialmente relacionadas con representaciones del Juicio Final. El añafil está presente en las justas medievales, en los pregoneros, en los toques que abrían los cortejos de algún festejo y en nuestro contexto como instrumento en ceremonias religiosas, incluso hoy día son utilizados en las procesiones de Semana Santa en Córdoba, España. (Figura 5)

El añafil es un instrumento sencillo y como trompeta natural el sonido va directo por la vibración del soplo de los labios del ángel músico que está provocando 
un toque de atención, anuncia la solemnidad del momento. Normalmente en un contexto religioso la trompetería son instrumentos que acompañan al coro de ángeles. El sonido que desglosa es único y contribuye de alguna forma a realzar la sonoridad musical del grupo.

Justamente en la otra parte de la tribuna se encuentra otra pintura con un ángel que interpreta un esquematizado bajón en el que se aprecia el tudel metálico; su música señala los sonidos más graves del grupo que conforman. El ángel músico realiza una ejecución musical adecuada, las manos están perfectamente colocadas para tañerlo, esto es, la izquierda encargada de las llaves superiores, en la parte superior, y la derecha en la inferior presionando los dedos sobre los orificios y entonando el punto bajo del concierto.

El bajón constituye uno de los instrumentos de viento-madera más importante del Renacimiento y que perdurará en el tiempo constituyendo una parte esencial en las capillas musicales a lo largo de su historia, de hecho, se decía que su función era "de iglesia". Su melodía acompaña tanto al canto llano, como al canto de órgano (polifonía) y en ocasiones sustituyendo el registro de voz del bajo, ya que se usaba para doblar la línea baja de la voz de los cantores de misas y motetes. Es un instrumento que forma parte de toda una familia de la misma gama, aunque no adquiere grandes modificaciones y perdurará en el tiempo conviviendo incluso con su sucesor, el fagot. (Figura 6)

La sonoridad que desprenden las pinturas murales de estas tribunas estaría dentro de las prácticas musicales de la época, por lo que bien podría sugerir una "Cantata Barroca" para bajo, un concierto vocal-instrumental con una parte vocal declamatoria cuyas voces recitativas sostienen la melodía. Estos ángeles cantores asumen un papel con la misma importancia que los instrumentistas. Igualmente, el acompañamiento musical lo ofrece una importante sección instrumental con el dúo de cuerdas que nos brindan la recreación de melodías, la expresividad del violín y el apoyo rítmico y armónico del bajo continuo del violonchelo que aludiría a la manifestación de la divinidad; todos a su vez, están determinados por el órgano de Santa Cecilia que marca la sonoridad. Esta tribuna de cuerdas expresa el sonido delicado e intimista de la composición añadiendo un ambiente de notas poéticas al que se une la empatía del arpa que tañe el rey David. En la segunda tribuna con el dúo de vientos se recrea una atmósfera sonora más potente, añadiendo a la composición orquestal timbres altos y más fuertes simbolizados por el poder de Dios. En realidad, los instrumentos como la trompeta, el bajón, el violín, el violonchelo, el órgano..., estarían en cualquier agrupación que implique la dinámica esencial de la música barroca.

Indudablemente estas tribunas también muestran una música que trasciende la conceptualización de un arte sonoro propiamente humano, los cantos y los instrumentos de viento y cuerda exploran hacia el ámbito sonoro de lo divino. Se puede apuntar que esta agrupación musical de ángeles y santos nos sorprenden con una bella melodía litúrgica, testimonio de las alabanzas divinas y que nada 
más entrar al recinto eclesiástico ofrecen a los fieles un auténtico concierto de gran musicalidad.

Siguiendo con el análisis asociativo sobre iconografía musical, nos merece especial interés el gran lienzo del presbiterio realizado por Lucas Valdés, David y el traslado del Arca de la Alianza a Jerusalén ${ }^{20}$. Se trata de una composición pictórica cuya escena alegórica religiosa reviste cierta complejidad, con una multitud de personajes que gesticulan con naturalidad y como telón de fondo un gran escenario, una interpretación de perspectivas arquitectónicas de la ciudad de Sevilla mediante ilusorias arquitecturas (puertas, murallas...), creando espacios decorativos muy conexos, aunque en realidad el acontecimiento se debió dar en Jerusalén. Este tipo iconográfico se basa en el texto del segundo libro de Samuel "Reunió de nuevo David a todo lo mejor de Israel, 30.000 mil hombres. Se levantó David y partió con todo el pueblo que estaba con él...cargaron el arca de Dios...David y toda la casa de Israel bailaban delante de Yahvé con todas sus fuerzas, cantando con citaras, arpas, adufes, sistros y cimbalillos" (2, S6).

En el centro de la escena y en primer plano David vestido de rey con su corona. Marcha tocando el arpa, avanzando con majestuosidad, adelantando el paso a modo de baile y cortejado por una agrupación femenina que también danzan y tocan instrumentos musicales. Se puede pensar que el pintor imprime un cierto concepto mediterráneo a esta obra pictórica, haciendo hincapié en instrumentos como el aulós, el pandero o las castañuelas. (Figura 7)

Este grupo musical va a la cabeza del largo cortejo y se puede intuir que marchan provocando un estruendoso y sonoro acompañamiento musical. Detrás sigue la gran procesión, transportando en andas el Arca de la Alianza, el candelabro de los 7 brazos, uno de los símbolos más conocidos del judaísmo ${ }^{21}$...etc., con una inmensa multitud: personajes orientales ataviados con turbantes; diferentes estamentos; numeroso grupo de prelados; órdenes religiosas y, contemplando todo, el pueblo, una muchedumbre que ha parado su actividad para ver el cortejo y a la espera del paso del Arca... Quizás como detalle anecdótico el pintor ha introducido a la derecha un perro aludiendo a la iconografía del mundo dominico.

En esta pintura se pueden apreciar grandes dotes del pintor Lucas Valdés que trabajó en la profusa ornamentación de la iglesia dominica entre 1709 y $1715^{22}$. Se distingue el dibujo y su paleta excepcional, como la monumentalidad de las figuras y los personajes con formas movidas y agitadas por la música, pero siempre con una ejecución serena, con rostros que no gesticulan excesivamente a pesar de que están de celebración por lo que resulta una composición dinámica pero no desenfrenada, podríamos clasificarlo como "barroco inhibido".

20 Fernández López, 2004: 57.

${ }^{21}$ Leipoldt/Grundmann, 1973: 53.

22 Fuentes Lázaro, 2009: 202. 
Iconográficamente la imagen bíblica del rey David como intérprete musical fue una de las más extendidas a través de la historia y constituyó uno de los paradigmas visuales de la música sacra. Su iconografía se apoya en pasajes bíblicos como en este caso al recibir el Arca de la Alianza en Jerusalén. Tradicionalmente David se ha asociado instrumentalmente con el arpa, aunque a veces aparece con otros instrumentos de cuerda.

En párrafos anteriores se han descrito algunas de las características del arpa, en esta ocasión David toca un arpa de estética más clásica, muy estilizada y elegante $^{23}$. Aunque se ha hecho más liviana, el instrumento queda ligeramente apoyado sobre su pierna y una de las figuras femeninas ha dejado de tocar sus castañuelas para prestar ayuda al rey y que este pueda ejecutar la melodía; no obstante, el instrumento aún no ha alcanzado las proporciones que llegará a desarrollar en tiempos posteriores. Se pueden observar las características organológicas del instrumento: columna recta, cuello horizontal curvado y una tabla de armonía liviana por lo que se trata de un arpa de resonancia cromática sin pedales, de 21 cuerdas. No se aprecian, aunque se suponen, las clavijas de la parte superior que sirven como mecanismo de afinación.

El arpa o la lira solían estar siempre presente junto al popular aulós, un instrumento musical con tubo doble de madera (también fabricado de caña o marfil), dotados de dos lengüetas dobles, con un número variable de orificios (de 4 a 6 ); en nuestra pintura se aprecian los seis orificios. Este doble tubo se tocaba a la vez para que sonara más vigoroso y se singulariza por su tesitura heterofónica caracterizada por la variación.

En nuestra pintura el "auleta" aparece ejecutando música presionando sus dedos sobre los orificios y soplando la boquilla, de forma que posiblemente está efectuando adornos musicales como trinos, mordentes, etc., se adivina que el sonido que transmite es una agradable melodía, dulce y penetrante, parecido al del actual oboe, y propicia un ambiente lleno de mucha festividad y júbilo.

Asistiendo al rey David y siguiendo sus pasos, cuatro mujeres con instrumentos de percusión que generalmente han estado asociados a la música profana. Realmente estos instrumentos no aportarán sonidos melódicos al conjunto orquestal que compone esta agrupación pero su contribución rítmica y colorista al desfile es fundamental.

Analicemos cada uno de ellos. En un primer plano una de estas mujeres toca una pandereta de forma circular, instrumento rústico constituido por un aro de madera que contiene un conjunto de sonajas (chapas de metal) o cascabeles y cubierto por una piel lisa y estirada que forma la membrana o parche del instrumento. La pandereta es un instrumento de percusión que puede clasificarse en la familia de los instrumentos membranófonos y su origen nos remite a

${ }^{23}$ Rodríguez Oliva, 2007: 93-121. Amplia información organológica, sobre formas y significado del arpa y otros instrumentos. 
civilizaciones de la antigüedad, siendo uno de los instrumentos más populares en todas las épocas y lugares; asimismo su uso se relaciona con las fiestas y procesiones, también para celebrar el regreso de algún héroe, etc.

La música de este instrumento da apoyo al grupo, realmente la pandereta es poco sonora porque no tiene caja de resonancia, pero ofrece un sonido muy característico. La intérprete sostiene la pandereta con una mano sobre un lado del aro de madera, se observa cómo los dedos no tocan la membrana por la parte posterior, lo que apagaría el sonido. También es apropiado el ángulo con el que la soporta, ni completamente vertical, ni estirada de forma horizontal, sino justo en la posición intermedia como bien nos muestra la intérprete logrando un mejor equilibrio en todas las vibraciones de los sonajeros. Esta pandereta expone dos sonoridades propias: por una parte, cuando las sonajas metálicas chocan entre sí, vibrando y generando sonido y, por otro lado, al ser percutida directamente con los dedos de la otra mano en la membrana, provoca una vibración que se extiende en la estructura generando otro tipo de sonido de menos intensidad.

Finalmente, prestando gran atención aparecen otras tres intérpretes con uno de los instrumentos más representativos de todo el Mediterráneo: las castañuelas o palillos. Igualmente, estos son instrumentos de percusión, esta vez de la familia de los idiófonos entrechocados.

Las mujeres sostienen las castañuelas de manera que las dos mitades cóncavas de madera quedan entre las manos, pero se pueden apreciar las cintas o cordones rojos que están en la orejilla del instrumento y que se colocan en el dedo pulgar para poder repicar con los demás dedos. Organológicamente este instrumento de percusión representado en esta obra pictórica es muy sofisticado y está dando apoyo a la estructura rítmica del cortejo.

Indudablemente la cabeza de esta comitiva ofrece una música divertida y colorida. Con instrumentos como el aulós, la pandereta y las castañuelas, el pintor ha introducido un carácter muy festivo a la obra pictórica. Este grupo musical desempeña un papel fundamental en la procesión estimulando al cante, al baile y a la algarabía. Al paso del grupo musical parece que todos quedan cautivados.

De similares características estéticas que la obra anterior y bajo un marco arquitectónico de tres vanos, articulado por columnas de capitel corintio, Lucas Valdés ${ }^{24}$ representa la pintura mural sobre la alegoría Entrada de San Fernando en Sevilla. En este caso todo un cortejo procesional de prelados de la Iglesia, santos, órdenes religiosas personajes con escudos reales, etc. acompañan a los monarcas que marchan con su guardia. Paralelamente la Virgen de los Reyes aparece transportada en andas y bajo palio, en marcha y de espaldas, camino a las murallas. Respecto al contexto y la iconografía de esta obra remito a Fernández López donde queda ampliamente definida.

${ }^{24}$ Fernández López, 2004: 79. 
Sin embargo, lo más significativo de la pintura para nuestro estudio, sería insistir en verificar cómo la música está presente en diferentes actos civiles y religiosos de la sociedad en estos casos ligados a la vida, a la alegría y a las festividades. Así pues, en un extremo de la pintura, destacados en un primer plano, observamos a músicos que acompañan a la comitiva con trompetas y timbales, y que van anunciando la llegada del rey Santo.

Efectivamente son sonidos de viento y percusión que tienen como misión avisar y comunicar la llegada de reyes. Agachado en un primerísimo plano de la pintura aparece un tamborilero. El mundo de los tambores nos remite a orígenes de épocas muy anteriores, su uso se pierde en el tiempo siendo uno de los instrumentos más antiguos y universales, y básicamente destaca por la sencillez y simpleza de su concepción, además de tener una amplia tipología instrumental. En nuestra pintura se muestra un instrumento de percusión que estaría en el grupo de los membranófonos percutidos. Generalmente el tambor está formado por una caja de resonancia cilíndrica y una o dos membranas que cubren los bordes del cilindro, es decir, cubren las aperturas de la caja de resonancia que en este caso es ovalada. Se observa un tambor decorado con banderolas de escudos de la realeza, con una caja de resonancia amplia y de forma semiesférica y el músico redobla sus baquetas produciendo gran sonido. Posiblemente el músico adquiere esa postura por la fuerza ejercida, provocando una sonoridad fuerte con entonaciones secas y agudas; los redobles y repiques proporcionan gran solemnidad al contexto pictórico.

Finalmente se hará mención especial, aunque necesariamente breve, a la escultura que queda casi invisible y que se encuentra ubicada en el retablo cuya titular principal es Nuestra Señora del Buen Consejo. Esta advocación se representa en un relieve que ocupa la hornacina del cuerpo principal y, aunque de trazas modernas, de Sebastián Santos, queda incrustado en un antiguo y anónimo retablo barroco de principios del siglo XVIII y que pertenecería a la iglesia del primer templo conventual ${ }^{25}$. Este retablo tal como hoy se presenta ha sufrido trasformaciones, ya que las esculturas se mueven según las estructuras lignarias y las razones que motivan esos cambios de ubicaciones casi siempre están relacionadas con fluctuaciones de modas y del gusto, pero sobre todo a la adecuación litúrgica.

El retablo actual se articula por un banco, un cuerpo de tres calles y ático. Originalmente, el retablo parece que estuvo dedicado a la beata Juana de Aza, madre de Santo Domingo de Guzmán, relieve que ocupa la hornacina central del ático, donde aparece la figura de la Santa sumida en un sueño frente a un altar en presencia de un ángel. En la parte central, a ambos lados divididos arquitectónicamente mediante columnas salomónicas, se pueden apreciar dos calles con hornacinas. En cada hornacina se halla una escultura, son unas tallas de bulto

${ }^{25}$ Fernández Rojas, 2008: 112. 
redondo; ambas anónimas, de estilo barroco, de madera policromada y de valiosa ejecución.

Iconográficamente se representa en un lado del retablo la escultura de Santa Catalina de Alejandría refrendada por sus indudables caracteres e interpretada como princesa coronada con su túnica y manto. También conserva sus atributos particulares, como la rueda dentada y quebrada (del suplicio), la espada (de la decapitación), y a sus pies el busto con la cabeza coronada del emperador (su perseguidor). Al otro lado del retablo, ofrecemos una nueva lectura iconográfica porque se trata de la escultura de Santa Cecilia, con la que rectificamos la Santa Bárbara refrendada por diferentes autores. En esta línea se debe interpretar que se trata de Santa Cecilia representada con su iconografía más usual: en una mano sostendría la palma (símbolo de todos los mártires), y en su mano izquierda lleva un pequeño instrumento en el que se pueden observar claramente los registros (en este caso cuatro) de la caja de un órgano manual o portátil. Además, contribuye a hacer más legible su identidad otro rasgo que la define. Se trata de su mirada, su rostro mira hacia arriba y sus ojos levantados hacia el cielo parecen conectar directamente con el coro de ángeles celestiales; de hecho, Santa Cecilia nunca mira partituras (representan la música terrenal), ella está absorta en la audición interior de la música "celestial", nos está recordando que su música se eleva y es una alabanza a Dios. Prácticamente hasta el Renacimiento su único atributo era la corona de flores y desde el siglo XIV se la representa con instrumentos musicales, principalmente el órgano, como es nuestro caso. La escultura reviste un especial interés como ejemplo de su patronazgo sobre la música, los músicos y los fabricantes de instrumentos.

Organológicamente el instrumento que lleva Santa Cecilia es un órgano portativo o positivo que pueden presentar tamaños y especificaciones concretas de teclas, fuelles y tubos, cuanto mayor sea, la tesitura se irá ampliando. En nuestro caso se trata de un pequeño órgano portativo llamado así por su amplia movilidad y porque se puede llevar en la mano. Su tesitura raramente era mayor de dos octavas y se puede tañer con una sola mano. La Santa no está interpretando música, simplemente muestra el instrumento como símbolo iconográfico de su patronazgo. (Figura 8)

A modo de conclusión, nuestro estudio presenta una amplia representación iconográfica de instrumentos musicales así como la ejemplificación de diversas propuestas interpretativas acordes con las prácticas musicales contemporáneas a las obras artísticas. Localizamos disímiles particularidades sobre la música en la iglesia parroquial de Santa María Magdalena de Sevilla y tras el estudio meticuloso organológico/iconográfico musical, también se propone una amplitud de miradas, y profundizar en la conceptualización de la música. Ciertamente, en esta propuesta no solo se trata de aprender a "escuchar" también se debe aprender a "mirar la música", analizando argumentaciones espaciales y las fuentes pictóricas o escultóricas que nos ayudan a entender los valores de la música representada y 
su propio contenido sonoro. En este análisis se ha contemplado que el poder de la música representada es espectacular en un ámbito casi invisible para muchos. Por otra parte, los instrumentos como recurso nemotécnico del arte sonoro del barroco cumplen en gran parte con sus características explícitas, aunque en ocasiones obedecen a una representación idiomática dirigida a un impacto visual, sobre todo cuando se pierden los detalles de los instrumentos. En general, la fidelidad de los instrumentos que portan es notable y en gran parte, las representaciones se ajustan a la morfología propia del instrumento. Efectivamente con este estudio se ha pretendido participar en un nuevo alcance del sentido de la representación artística, incidiendo en diferentes aspectos sonoros que nos introducen al conocimiento del alma de la obra artística y sonora de una época.

Fecha de recepción: 27 de octubre de 2020.

Fecha de aceptación: 2 de mayo de 2021.

\section{BIBLIOGRAFÍA:}

Ayarra Jarne, José Enrique (1998): Órganos en la provincia de Sevilla inventario y catálogo. Sevilla: Consejería de Cultura de la Junta de Andalucía.

Fernández López, José (2004): Lucas Valdés (1661-1725), Sevilla: Diputación de Sevilla.

Fernández Rojas, Matilde (2008): Patrimonio artístico de los conventos masculinos desamortizados en Sevilla durante el siglo XIX: benedictinos, dominicos, agustinos, carmelitas y basilios. Sevilla: Diputación de Sevilla.

Fuentes Lázaro, Sara (2009): "La práctica de la cuadratura en España: el caso de Lucas Valdés (1661-1725)". En: Anales de Historia del Arte, 19, pp.195-210.

Gutiérrez Cordero M. ${ }^{a}$ R., (2008): La Música en la Colegiata de San Salvador. Sevilla: Consejería de Cultura de la Junta de Andalucía.

Hernández Díaz, José (1980): "La parroquia sevillana de Santa María Magdalena”. En: Boletín de Bellas Artes, 8, pp. 203-236.

Isusi Fagoaga, Rosa/Gembero Ustárroz, María (2002): "La música en la Catedral de Sevilla en el siglo XVIII". En: Revista de musicología, vol. 25, 2, pp. 577-580.

Labat, Jean-Baptiste (2007): Viaje por Andalucía en los años 1705 y 1706. Sevilla: Ed. Renacimiento, S.A.

Leipoldt, Johannes/Grundmann, Walter (1973): El mundo del Antiguo testamento. Madrid: Ediciones Cristiandad.

Martín Pradas, Antonio (2004): Sillerías de coro de Sevilla. Análisis y evolución. Sevilla: Guadalquivir ediciones.

Montoya Alabau, José (2009): "Leonardo de Figueroa. Un arquitecto utielano fundador del barroco sevillano". En: Oleana, 24, pp. 295-340. 
Peñas Serrano, Pablo (2005): “La música en los conventos dominicanos de Toledo (siglos XVI-XVIII)”. En: Anales toledanos, 41, pp. 255-316.

Pinto Puerto, Francisco (2015): "El coro del monasterio dominico de San Pablo de Sevilla". En: Villaseñor Sebastián, Fernando/Teijeira Pablos $\mathrm{M}^{\mathrm{a}}$ Dolores/ Muller Welleda/Billiet Frédéric: Choir Stalls in Architecture and Architecture in Choir Stalls, Cambridge: Cambridge Scholars Publishing, pp. 357-373.

Roda Peña, José (2016): "Nuevas noticias sobre la ruina y reconstrucción de la iglesia del Real Convento de San Pablo de Sevilla, según un manuscrito inédito de 1692-1708. Sevilla”. En: Revista de Humanidades, 27, pp. 193-232.

Rodríguez Oliva, M. a Carmen (2007): "Música y arte, arte y música, su relación”. En: Martín Pradas, Antonio (coord.): Actas de las V Jornadas de Protección del Patrimonio Histórico de Écija. "Protección y Conservación del Patrimonio Intangible o Inmaterial”. Écija: Asociación de Amigos de Écija, pp. 93-121.

Rodríguez Oliva, M. ' Carmen/Osuna Lucena, M. a Isabel/Sánchez Rodríguez, Antonio (2018): "Lienzos sonoros de Murillo". En: Cuadernos de Amigos del Museo de Osuna, 20, pp. 80-89.

Ruiz Jiménez, Juan (2018): Órgano del Evangelio del convento de San Pablo (1741). Paisajes Sonoros Históricos. http://www.historicalsoundscapes.com/ evento/802/sevilla/es (12-09-2020). 


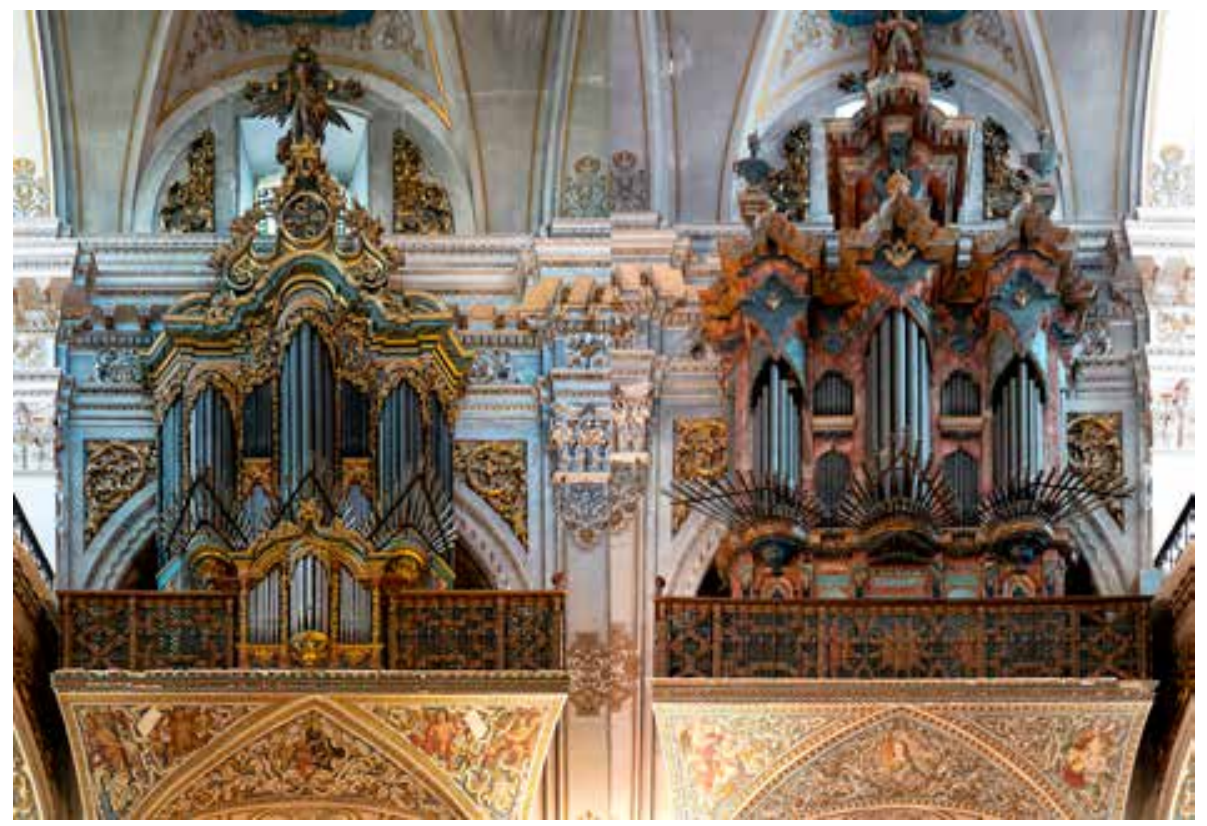

Figura 1. Órganos, siglo XVIII, parroquia de Santa María Magdalena, Sevilla. Fotografía J. M. Acebes Ruiz. 


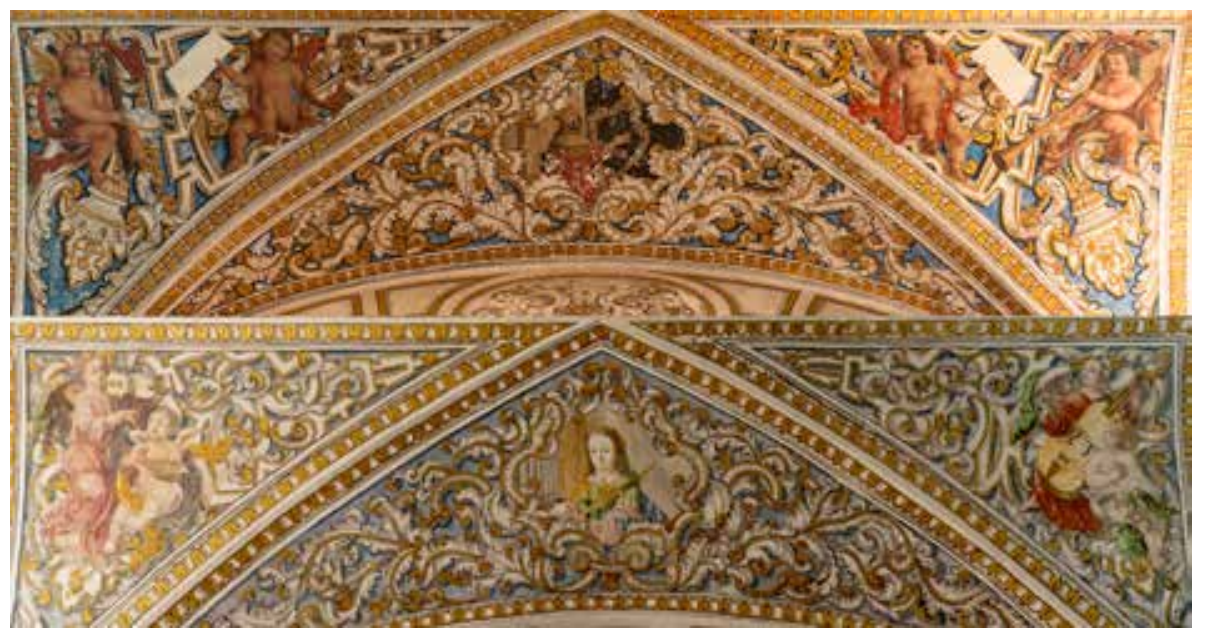

Figura 2. Anónimo, pinturas tribunas de los órganos, siglo XVIII, parroquia de Santa María Magdalena, Sevilla. Fotografía J. M. Acebes Ruiz. 


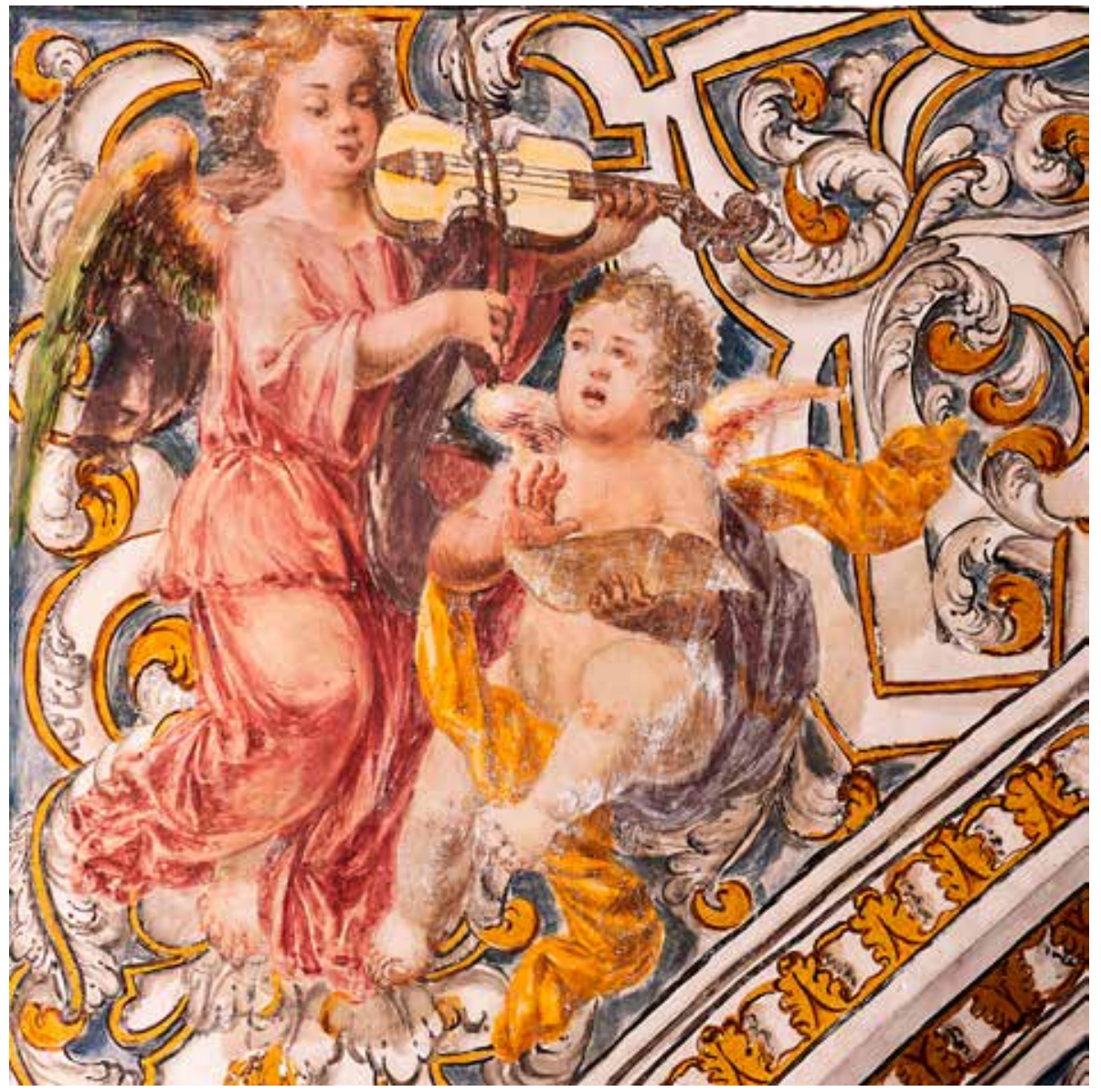

Figura 3. Anónimo, ángel músico con violín, siglo XVIII, parroquia de Santa María Magdalena, Sevilla. Fotografía J. M. Acebes Ruiz. 


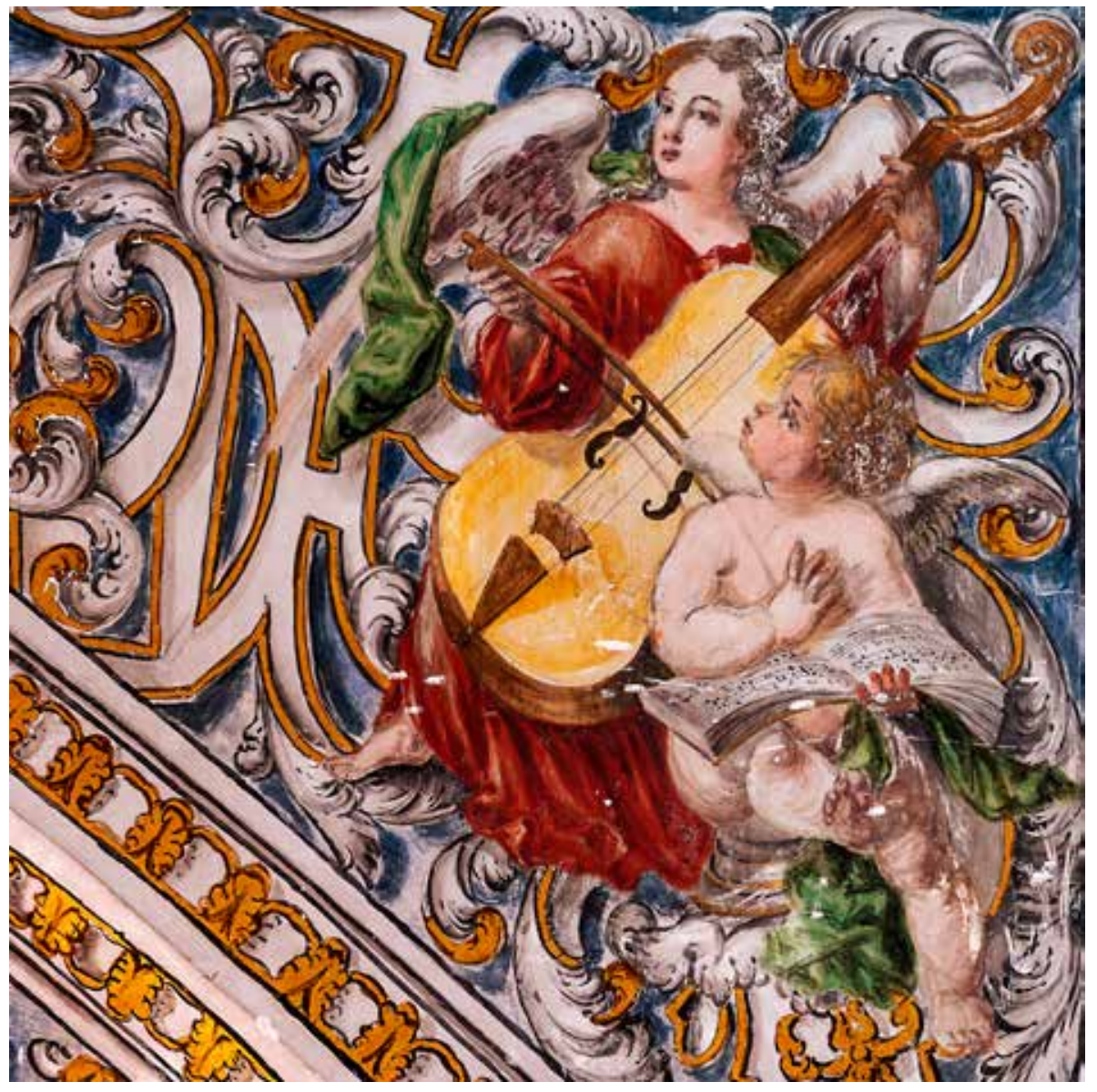

Figura 4. Anónimo, ángel músico con violonchelo, siglo XVIII, parroquia de Santa María Magdalena, Sevilla. Fotografía J. M. Acebes Ruiz. 


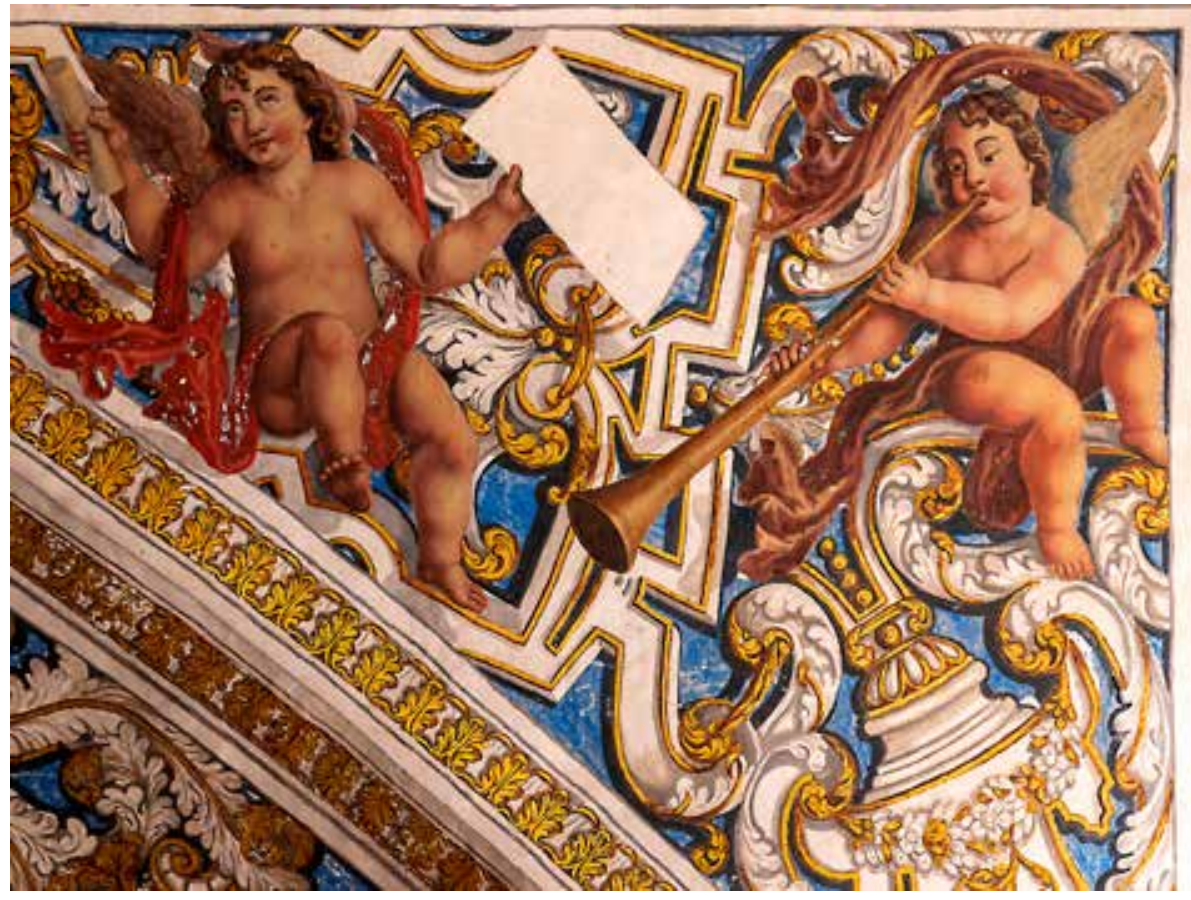

Figura 5. Anónimo, ángel músico con añafil, siglo XVIII, parroquia de Santa María Magdalena, Sevilla. Fotografía J. M. Acebes Ruiz. 


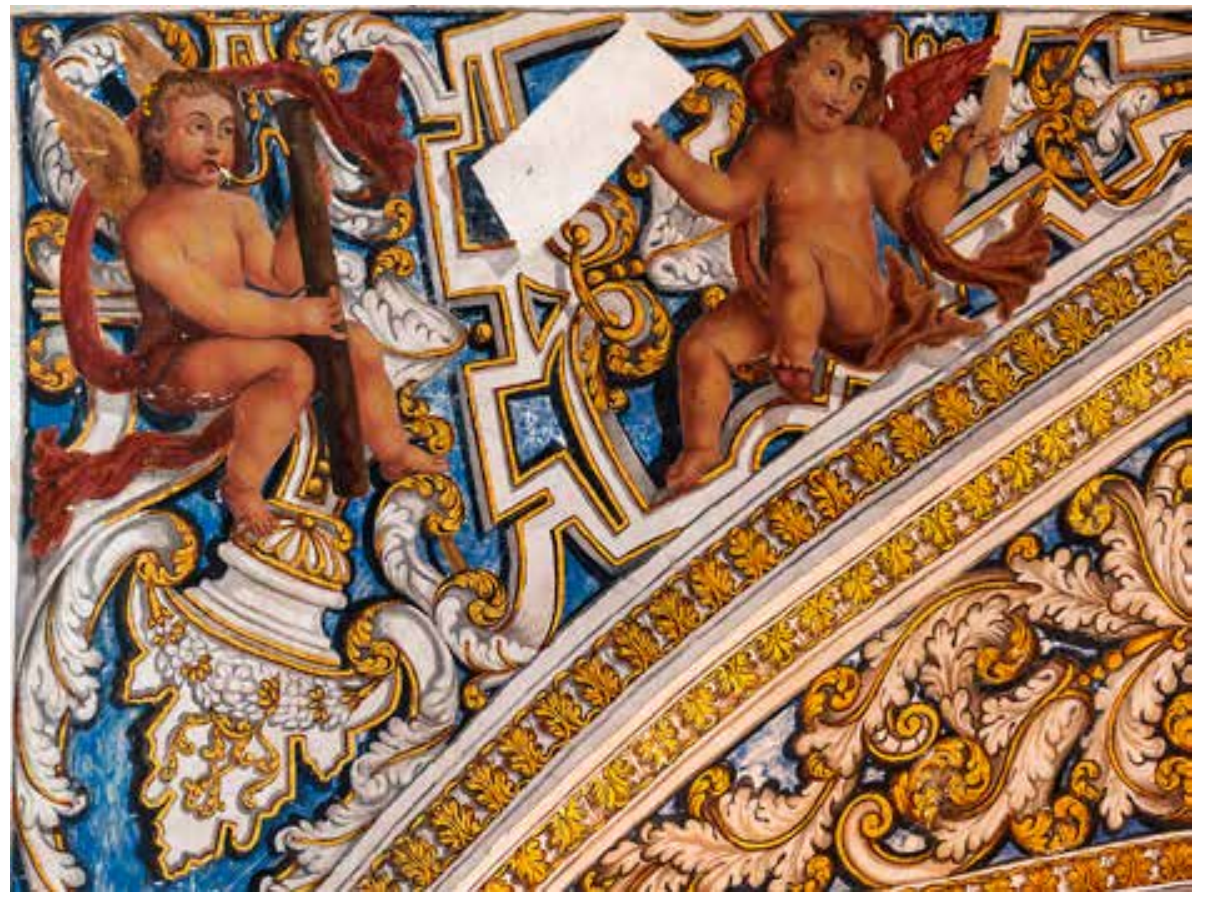

Figura 6. Anónimo, ángel músico con bajón, siglo XVIII, parroquia de Santa María Magdalena, Sevilla. Fotografía J. M. Acebes Ruiz. 


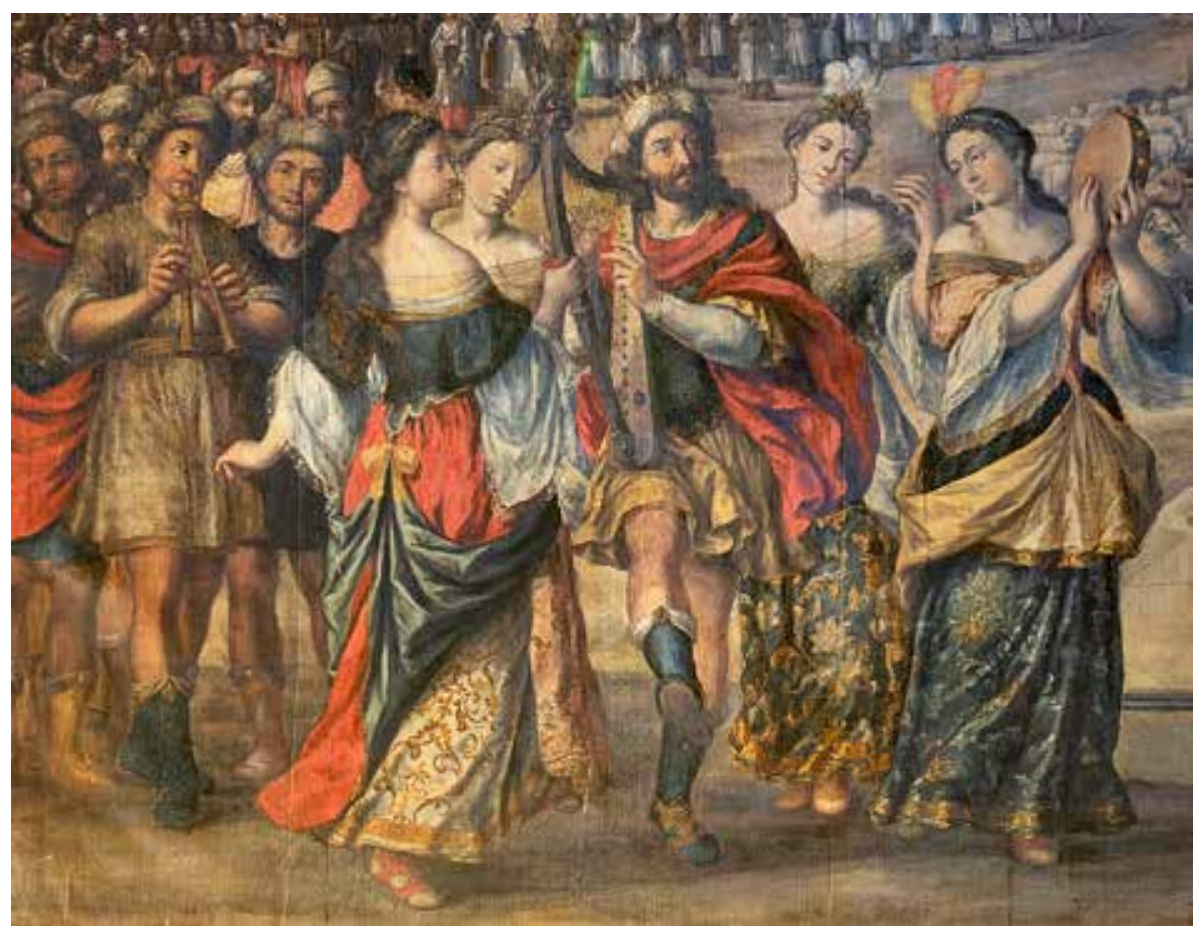

Figura 7. L. Valdés, detalle agrupación musical de David y el Traslado del Arca de la Alianza a Jerusalén, siglo XVIII, parroquia de Santa María Magdalena, Sevilla. Fotografía J. M. Acebes Ruiz. 


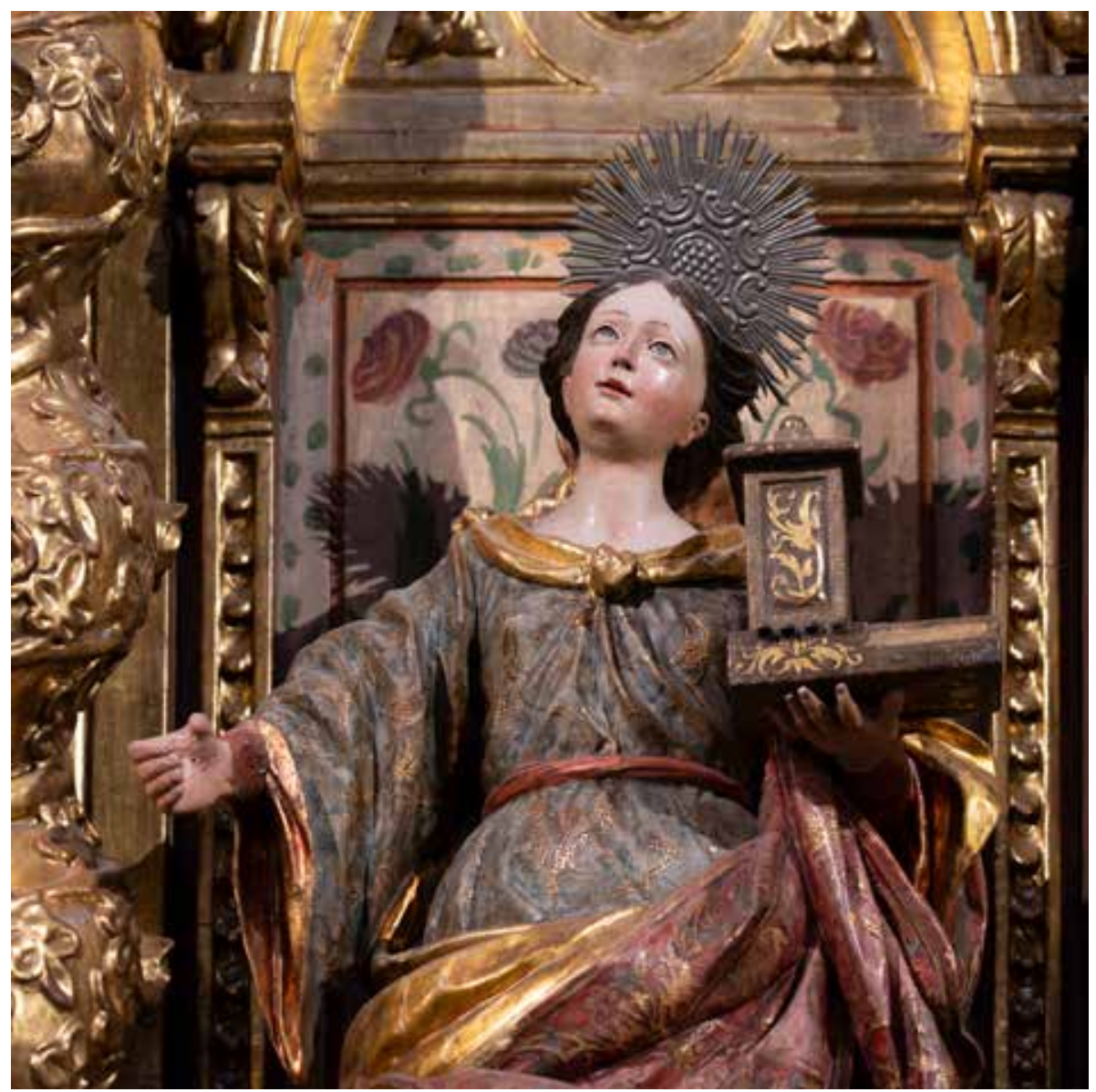

Figura 8. Anónimo, detalle escultura de Santa Cecilia, retablo de Nuestra Señora del Buen Consejo, siglo XVIII, parroquia de Santa María Magdalena, Sevilla. Fotografía J. M. Acebes Ruiz. 